\title{
Reduction of Effects of High-Frequency Noise on SQUID Magnetometer Using High-bandwidth Feedback Electronics
}

\author{
D. Oyama, M. Miyamoto, M. Higuchi, G. Uehara, H. Kado, and K. Kobayashi* \\ Applied Electronics Laboratory, Kanazawa Institute of Technology, 3 Amaike, Kanazawa, Ishikawa 920-1331, Japan \\ ${ }^{*}$ Faculty of Engineering, Iwate University, 4-3-5, Ueda, Morioka, Iwate 020-8551, Japan
}

\begin{abstract}
We report the potential of high-bandwidth feedback electronics to reduce the effects of high-frequency noise on a SQUID magnetometer. We developed a parallel type FLL system that has two feedback loops. One loop acts as a magnetometer for low-frequency magnetic signals (FLL-L). The other reduces high-frequency magnetic noise (FLL-H). The prototype of the parallel FLL system is designed to have a bandwidth of DC to $1 \mathrm{kHz}$ for FLL-L and $40 \mathrm{kHz}$ to 4 $\mathrm{MHz}$ for FLL-H. We carried out some experiments to the demonstrate efficacy of the parallel type FLL. The effects of high-frequency noise effects on a SQUID magnetometer were reduced by FLL-H in observation of $\Phi-V$ characteristics and measurement of magnetic noise performance.
\end{abstract}

Key words: SQUID, flux-locked loop (FLL), bandwidth, high-frequency noise effects

\section{高帯域フィードバック回路を用いた SQUID 磁束計における高周波ノイズ影響の緩和}

\author{
小山大介・宮本政和・樋口正法 -上原弦・賀戸久 - 小林宏一郎* \\ 金沢工業大学先端電子技術応用研究所, 石川県金沢市天池町 3（干920-1331） \\ *岩手大学工学部，岩手県盛岡市上田 4-3-5（广020-8551）
}

\section{1. はじめに}

近年, SQUID (Superconducting Quantum Interference Device：超電導量子干渉素子) を用いた生体磁気計測，非破壊検 査 ${ }^{1)}$, 免疫反応の測定 2 など様々な磁気計測が行われている. これ らは，磁気シールドルームを用いずに安定して動作する SQUID 磁束計へのニーズが高い. 磁気シールドルームが必要な理由とし て, SQUID 磁束計の感度が非常に高いため, 生体磁場などの微弱 な信号に対して地磁気などの大きな磁場を遮蔽する必要があるこ とや, RF ノイズなどの高周波磁気ノイズによって SQUID 磁束計 が動作しなくなるなどが挙げられる. 著者らは前者の問題に対し て広いダイナミックレンジなシステムの開発を行ってきた ${ }^{3)}$. 本論 文では後者の問題に着目し, 高周波磁気ノイズが存在する環境で も安定に動作する SQUID 磁束計システムの開発を目的とする.

SQUID は数 $\mathrm{GHz}$ 以上の周波数帯域を持つと言われている4)が, 磁束計として用いる場合の周波数帯域は信号線や電子回路により 制限される. 一般に生体磁気計測に用いる SQUID 磁束計は直流 から $10 \mathrm{kHz}$ 程度の周波数帯域を持つ. $\mathrm{RF}$ ノイズなどのこれより も高い周波数の磁気ノイズが印加されると動作が不安定になり， 計測に影響を及ぼすことが広く知られている 5),6).SQUID を動作 させる際に SQUID の近くに電磁皮を発生させる機器を置かない ことや電磁シールドを用いることは，もはや常識となっており， SQUID 磁束計の利用範囲を制限する要因の一つでもある.

そこで著者らは測定対象信号の周波数帯域用の電子回路 (Flux -Locked Loop：FLL 回路）とは別に，より高い周波数をフィード バックし，高周波ノイズを打ち消寸方法としてハイブリッド方式 FLL を開発した ${ }^{7)}$. この方法によって数 $\mathrm{kHz}$ 以下の低周波部にお
ける広いダイナミックレンジと, $20 \mathrm{kHz}$ 程度の動作領域を得るこ とができたが，それ以上に高い周波数のノイズに対しては効果が 得られなかった.

本論文では，より高い周波数の磁気ノイズを打ち消す電子回路 を製作し, SQUID 磁束計における高周波磁気ノイズ影響の緩和に 関する本手法の有効性を調査した.

\section{2. 並列型 FLL 回路の原理}

SQUID の入出力特性である磁束電圧特性 $(\Phi-V$ 特性) は周期 性を持つ非線形である. 動作点付近の極めて小さい信号を扱う場 合には線形に近似して信号を計測することが可能だが，一般的に はFLL 回路を用いて特性を線形化し，ダイナミックレンジを広げ て利用されている. SQUID はrf-SQUID とdc-SQUID，FLL は変調型と直接帚還型としてそれぞれ二つに分類される. 本論文 では，生体磁気計測で多く使われる dc - SQUID と直接帚還型 FLL を用いることを前提とする.

Fig.1に本研究で開発する並列型FLL回路のブロック図を示す. 本システムは低周波をフィードバックする回路と高周波をフィー ドバックする二つの回路を並列に利用する. 本論文では, 低周波 側の回路を FLL-L, 高周波側の回路を FLL-H と呼ぶこととする. 前述のハイブリッド方式はFLL-Lに相当する部分がディジタル回 路によって構成されていたが，本論文では簡単のため, より一般 的なアナログ回路による FLL を使用する.

低周波側の回路は従来の直接帰還型 FLL 回路と同様に, プレア ンプと積分器によって構成される. SQUID の出力電圧をプレアン プによって増幅し, 積分器に入力する. 積分器の出力信号はフィ ードバックコイルによって SQUID にフィードバックされる. 外 


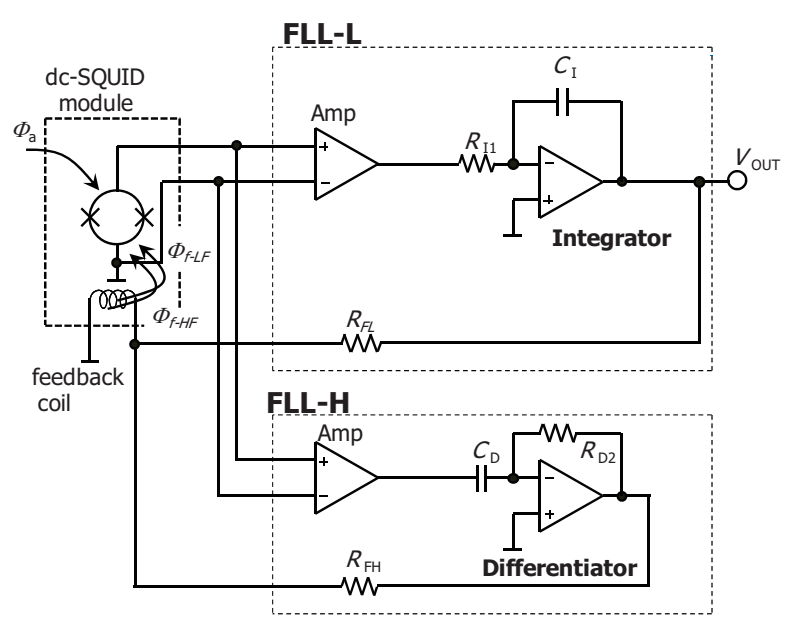

Fig. 1 Schematic of parallel FLL.

部から印加される磁束 $\Phi_{a}$ と等しい大きさの磁場が逆位相でフィ ードバックされ, SQUID に印加される磁束が打ち消され, 磁束が 動作点にロックされる.

FLL-L の周波数帯域はフィードバック系におけるスルーレート や時定数によって決まり，それよりも高い周波数の磁束信号また は磁束ノイズに対してはフィードバックにより磁束を打ち消すこ とができない，一方，磁束信号の検出部である SQUID 自体は非 常に高い周波数帯域を持つため，高周波の磁束に対しても電圧を 出力寸る。帯域以上の電圧信号が入力された電子回路は， $\Phi-V$ 特性の非線形性における復調効果によって，これを平均化した電 圧を低周波の磁束入力として捉えてしまう4). 低周波の磁気信号に 対しても正しいフィードバックを行うことができなくなる.

そこで，本手法では高周波の磁束をフィードバックすることに よって打ち消し，低周波側の FLL 動作への影響を緩和寸る．高周 波フィードバック回路は, プレアンプ及び微分器によって構成さ れ，FLL-L と並列に接続される．前述のように通常の FLL には 積分器を用いるが，ここでは高周波成分のみをフィードバックす るため微分器を用いる構成となっている.

FLL-L と FLL-H における積分器及び微分器の出力信号はフ イードバックコイルを介して SQUID にフィードバックされる. 各ループにおけるノイズの影響を避けるためにフィードバックコ イルを別にするのが最善と考えられるが，通常は SQUID とフィ ードバックコイルは一つモジュールとしてパッケージされてい るため, 一つのフィードバックコイルを共有することとした：二 つのフィードバック信号はキルヒホッフの第一法則に従い，電流 の和としてコイルに流れる.

また, SQUID の出力電圧を増幅するプレアンプを FLL-L と FLL-H において分けることにより, 市販されているオペアンプに よる回路構成を実現している，一方，並列にすることで回路の規 模が 2 倍になり, 大きさや価格, 回路パラメータ数, チューニン グの手間などの面でのデメリットもある．並列型でない一般的な 構成の FLL 回路に対して低雑音でかつ，高帯域のオペアンプを用 いることが理想ではあるが，両方の特性を満足するオペアンプを 用いることは困難である。そこで，低周波部にはさほど周波数帯

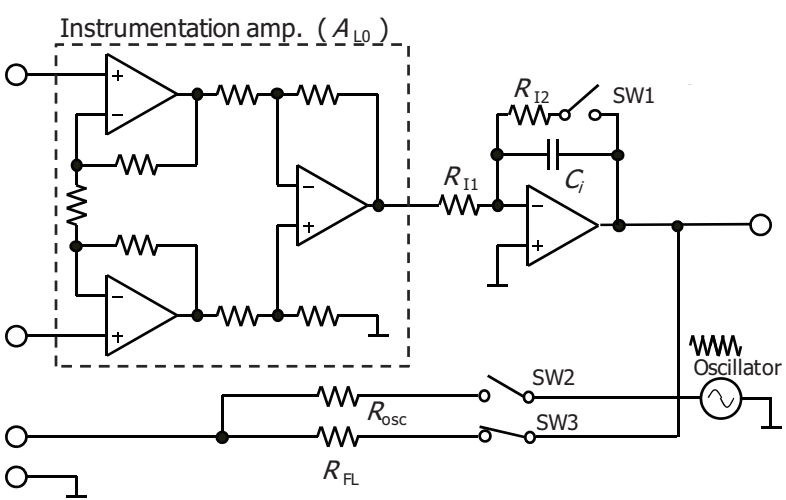

(a) Electronics of FLL-L.

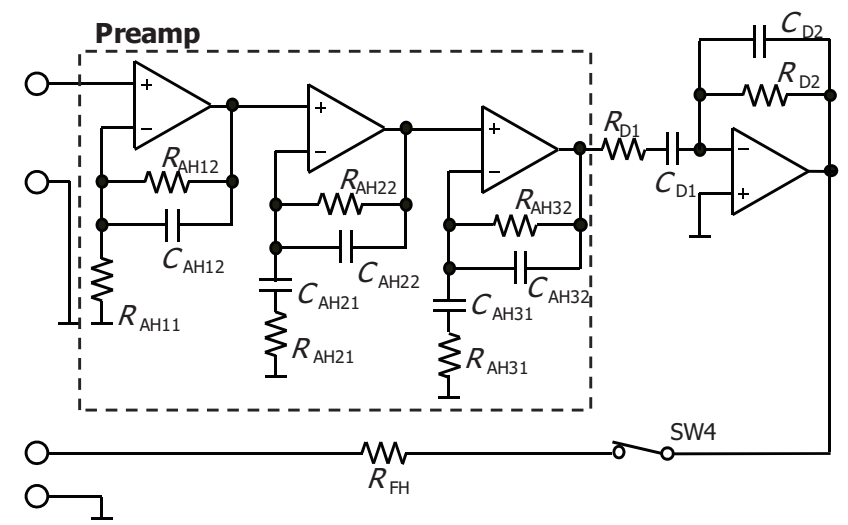

(b) Electronics of FLL-H.

Fig. 2 Prototype electronics for parallel FLL.

域は広くないが杂隹音は小さいオペアンプ，高周波部には杂隹音は大 きいが周波数帯域が広いオペアンプとして役割を分担することに より，並列型FLL回路を構成することができる.

\section{3. 回路の構成及び特性}

\section{1 回路構成}

Fig.2 に試作した回路の構成を示寸.（a）は FLL-L，(b) は FLL-H をそれぞれ示している. 前述の通り，FLL-L はプレアン プと積分器によって構成される. プレアンプは低ノイズの計装ア ンプを用いた．また，実際にはバイアス電流を印加する回路と， SQUID のオフセット電圧を調整するための回路も設けた. これら はFLL としての特性に直接関係しないため, Fig. 2 では省略して いる. 第 4 章にて記述するが, SQUID の $\Phi-V$ 特性の観測にも用 いることができるよう, 積分器のスイッチと発振器から磁束信号 を印加する部分も設置した. プレアンプには市販の低ノイズアン プを使用した。

FLL-H は高速アンプをプレアンプとして用いるため, シングル エンド入力とした．一つのオペアンプでは GB 積が限られる．そ こで, 低増幅率・高帯域のアンプ回路 3 段並ベてプレアンプを構 成している．ここでは高周波成分のみフィードバックすることを 目的としており, SQUID のオフセット電圧を無視するため, プレ アンプは高周波成分のみを増幅する構成とした。 また，プレアン プには市販の高速アンプを使用した。 
Table 1 Parameters of the parallel FLL electronics.

\begin{tabular}{|c|c|c|c|c|c|}
\hline$A_{\mathrm{L} 0}$ & 1110 & $R_{\mathrm{FH}}$ & $270 \mathrm{k} \Omega$ & $R_{\mathrm{AH} 31}$ & $5 \Omega$ \\
\hline$R_{\mathrm{I} 1}$ & $10 \mathrm{k} \Omega$ & $R_{\mathrm{AH} 11}$ & $5 \Omega$ & $R_{\mathrm{AH} 32}$ & $100 \Omega$ \\
\hline$R_{\mathrm{I} 2}$ & $5 \mathrm{k} \Omega$ & $R_{\mathrm{AH} 12}$ & $100 \Omega$ & $C_{\mathrm{AH} 32}$ & $1 \mu \mathrm{F}$ \\
\hline$C_{\mathrm{I}}$ & $2200 \mathrm{pF}$ & $C_{\mathrm{AH} 12}$ & $200 \mathrm{pF}$ & $C_{\mathrm{AH} 32}$ & $200 \mathrm{pF}$ \\
\hline \multirow[t]{4}{*}{$R_{\mathrm{FL}}$} & $22 \mathrm{k} \Omega$ & $R_{\mathrm{AH} 21}$ & $5 \Omega$ & $R_{\mathrm{AH} 41}$ & $47 \Omega$ \\
\hline & & $R_{\mathrm{AH} 22}$ & $100 \Omega$ & $R_{\mathrm{AH} 42}$ & $5.1 \mathrm{k} \Omega$ \\
\hline & & $C_{\mathrm{AH} 21}$ & $1 \mu \mathrm{F}$ & $C_{\mathrm{AH} 42}$ & $2200 \mathrm{pF}$ \\
\hline & & $C_{\mathrm{AH} 22}$ & $200 \mathrm{pF}$ & $C_{\mathrm{AH} 42}$ & $200 \mathrm{pF}$ \\
\hline
\end{tabular}

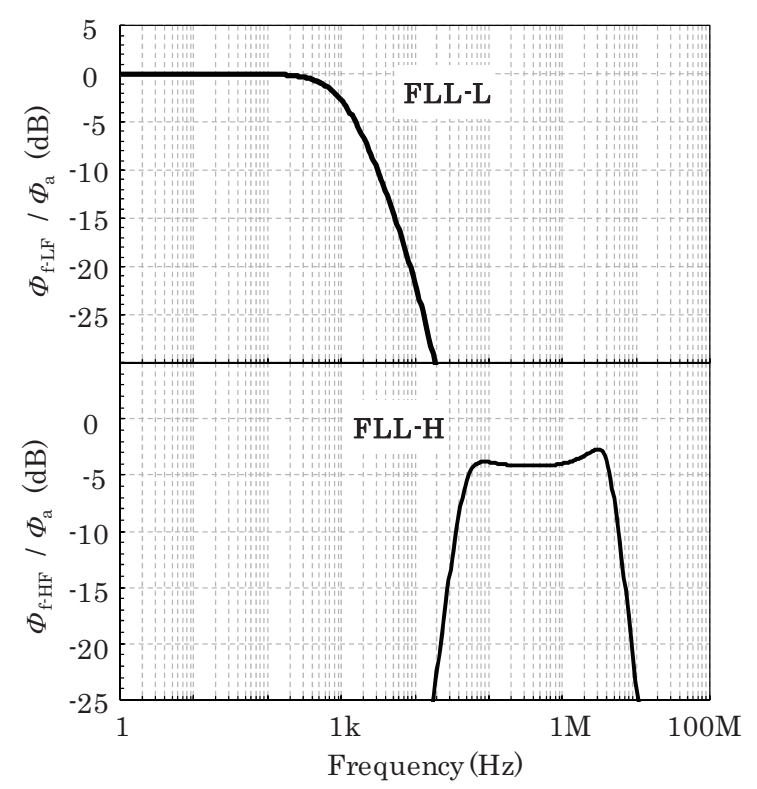

Fig. 3 Transfer functions of parallel FLL.

また，第 2 章では微分器を用いると述べたが，微分器における 高周波ノイズの過増幅や電源電圧の制限による不安定動作を防ぐ ため, $R_{\mathrm{D} 1}$ と $C_{\mathrm{D} 2}$ によってバンド・パス・フィルタを用いた回路 構成とした. $C_{\mathrm{AH} 12} ， C_{\mathrm{AH} 22} ， C{ }_{\mathrm{AH} 32}$ は各オペアンプの発振を 防ぐためのコンデンサである.

\section{2 特性シミュレーション}

本論文では, 並列型 FLL 回路の動作原理の実証を目的として, 以下のように試作回路を設計した. FLL-L は一般的に生体磁気計 測で用いられる直流から $1 \mathrm{kHz}$ までの周波数帯域を持たせた.

FLL-H は FLL-L と干渉しないように周波数帯域を離すため，低 域の遮断周波数を $40 \mathrm{kHz}$ とした. また, 電子回路の発振を抑える ため, 高域の遮断周波数が $4 \mathrm{MHz}$ となるように回路素子のパラメ 一タを決定した. Table 1 に試作回路における主な素子のパラメー タを示す.

これらの条件を用いて周波数特性に関するシミュレーションを 行った結果を Fig.3に示す. シミュレーションは市販の電子回路シ ミュレータにより行った. FLL-L がロー・パス・フィルタに似た 特性, FLL-H がバンド・パス・フィルタに似た特性を有するこ とが分かる. なお, FLL-H では平坦域のゲインが $0 \mathrm{~dB}$ に達して いないが, これは回路に微分器ではなくバンド・パス・フィルタ

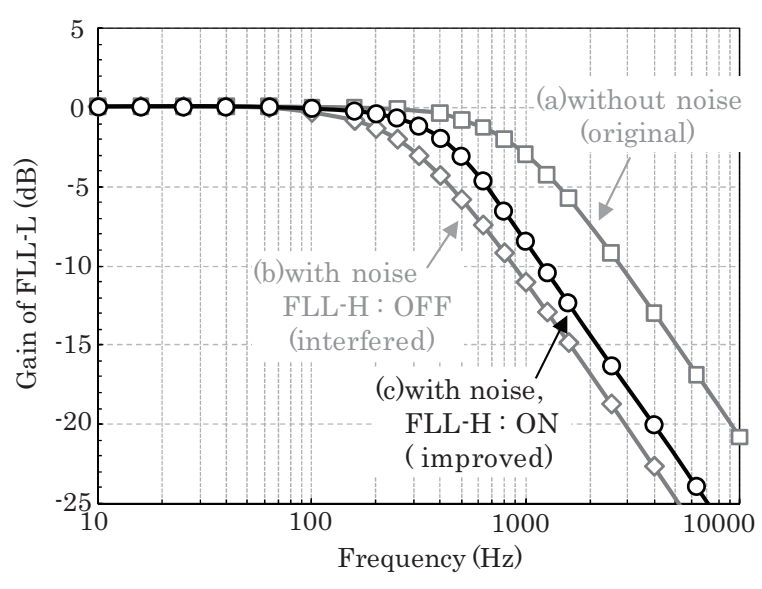

Fig.4 Frequency response of FLL; (a) the original frequency response. Bandwidths decreased in (b) due to interference of high-frequency noise. FLL-H improved the frequency response in (c).

を用いたことによって，理想的な微分器と異なる回路特性を持っ たためである.

\section{4. 動作実験}

並列型FLLによる高周波ノイズ影響の緩和を確認するため, 高 い周波数の磁気ノイズが存在する場合の SQUID 磁束計の動作特 性を, SQUID の $\Phi-V$ 特性における出力電圧勾配 $(d V / d \Phi)$ 及 び周波数特性と, 磁束ノイズレベルの二点から評価した。

\section{4. $1 \mathrm{SQUID}$ の出力電圧勾配 $(d V I d \Phi)$ の比較}

$\mathrm{RF}$ ノイズなど $\mathrm{SQUID}$ 磁束計の周波数帯域を超える周波数の磁 気ノイズが存在する環境では, SQUID の出力電圧勾配 $(d V / d \Phi)$ が減少する. 本論文では擬似的に高周波ノイズを印加し, 高周波 フィードバックを利用した場合と利用しない場合の $d V / d \Phi$ の比 較を行った。

SQUID の $\Phi-V$ 特性を観測し，特性における最大の傾きを $d V / d \Phi$ として導出した. $\Phi-V$ 特性はFLL-L 回路を利用して観 測を行った. Fig.2（a）におけるSW1をONにすることによって 積分器が LPF になり, SW2 を $\mathrm{ON}, \mathrm{SW} 3$ を OFF にすることに よってフィードバックコイルへ発振器からの信号を電流として印 加することができる. 発振器からは三角波信号を印加し, $V_{\text {out }}$ の 電土波形を計測することによって SQUID の $\Phi-V$ 特性が観測さ れる. 本研究で使用した SQUID $の ~ d V / d \Phi$ は $234 \mu \mathrm{V} / \Phi_{0}$ であっ た.

液体ヘリウム中の SQUID センサの寸ぐ横にコイルを置き, 擬 似的な高周波ノイズとして Fig.2（a）の発振器とは別の発信器か ら $1 \mathrm{MHz}$ の正弦波状の磁場を印加すると $d V / d \Phi$ は $82 \mu \mathrm{V} / \Phi_{0}$ に減少した. ここで, Fig.2 (b) における SW4 を ONにし, 高 周波フィードバックを実行すると, $d V / d \Phi$ は $120 \mu \mathrm{V} / \Phi_{0}$ と, $16 \%$ ほど改善した.

Fig. 4 にFLL-L の周波数特性を示す. ここではSW1, SW2 を OFF, SW3 をONにすることによって回路にFLL動作をさせる.

（a）は高周波磁気ノイズを印加しない場合，(b) は高周波ノイズ 
Table 2 Improvement in characteristics of SQUID magnetometer.

\begin{tabular}{|c|c|c|}
\hline & $d V / d \Phi$ & cut-off frequency \\
\hline $\begin{array}{c}\text { (a) Without noise } \\
\text { FLL-H : OFF } \\
\text { (original) }\end{array}$ & $\begin{array}{c}234 \mu \mathrm{V} / \Phi_{0} \\
(1.00)\end{array}$ & $\begin{array}{c}1 \mathrm{kHz} \\
(1.00)\end{array}$ \\
\hline $\begin{array}{c}\text { (b) With noise } \\
\text { FLL-H : OFF } \\
\text { (interfered) }\end{array}$ & $\begin{array}{c}82 \mu \mathrm{V} / \Phi_{0} \\
(0.35)\end{array}$ & $\begin{array}{c}310 \mathrm{~Hz} \\
(0.31)\end{array}$ \\
\hline $\begin{array}{c}\text { (c) With noise } \\
\text { FLL-H : ON }\end{array}$ & $\begin{array}{c}120 \mu \mathrm{V} / \Phi_{0} \\
(0.51)\end{array}$ & $\begin{array}{c}500 \mathrm{~Hz} \\
(0.50)\end{array}$ \\
\begin{tabular}{c} 
(improved) \\
\hline
\end{tabular} & \\
\hline
\end{tabular}

を印加したが高周波フィードバックを行わない場合，(c) は高周 波ノイズを印加し，さらに高周波フィードバックを実行した場合 における特性である。（a）は高周波磁気ノイズを印加しない場合 であり，Fig.3 と同様に $1 \mathrm{kHz}$ の周波数帯域が得られているが, (b) 及び (c) ではカットオフ周波数がそれぞれ $310 \mathrm{~Hz}, 500 \mathrm{~Hz}$ となった.

Table 2 に各条件における $d V / d \Phi$ 及びカットオフ周波数を示 す.（ ）内で示した数值は（a） 高周波ノイズを印加しない場合 の值を 1.00 とした場合の比であり，カットオフ周波数が SQUID の $\Phi-V$ 特性における $d V / d \Phi$ に比例していることが分かる. 通常, FLLにおけるスルーレート, 寸なわち周波数帯域は $d V I d \Phi$ に比例する ${ }^{8)}$.この結果から, SQUID の $d V / d \Phi$ が改善しただ けでなく, SQUID 磁束計の周波数帯域としても約 $20 \%$ 程度改善 していることが分かる.

\section{2 ノイズレベル計測}

次に，FLL-L での磁場計測における高周波ノイズの影響を比較 するため, ノイズレベルの計測を行った。 ここでは擬似的な高周 波ノイズの一例として $1 \mathrm{MHz}$ の正弦波を 10 波形ずつ $1.67 \mathrm{~ms}$ 毎 $(600 \mathrm{~Hz})$ に発生するバースト波を，液体ヘリウム中のSQUID センサのすぐ横に置いたコイルから印加した.

Fig.5 に高周波ノイズを印加しながら FLL-Lによって計測した 磁束ノイズスペクトルを示す．灰色線 が FLL-H による高周波つ イードバックを行わなかった場合，黒色線 が高周波フィードバッ クを行った場合のスペクトルである．前者では変調周波数である $600 \mathrm{~Hz}$ とその高調波にピークが現れているが, 後者では高周波ノ イズがキャンセルされ，ピークが小さくなっているのが分かる.

\section{5. 考察}

FLL-H によって周波数特性が回復していることから，， イズの緩和に関する本手法の有効性が認められる.ただし, FLL-H によって高周波フィードバックを行った場合でも $d V / d \Phi$ やカ⿻トオフ周波数が完全に回復されていない. Fig.3（b）の FLL-H の周波数特性を見ると $1 \mathrm{MHz}$ で約 -4 dB となっており, 入力磁束を完全に打ち消すことがで きなかったためである．特性をより回復させるためには， ゲインや周波数帯域をより向上させた FLL-H が望まれる.

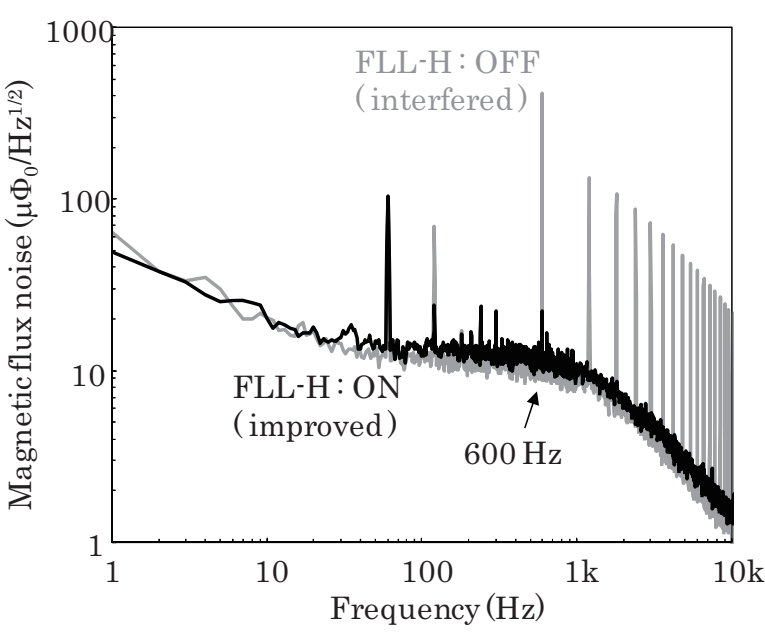

Fig. 5 Noise spectra signal of FLL-L with and without FLL-H operation.

一方, Fig.5 における $600 \mathrm{~Hz}$ のピークを見ると, FLL-H によって約 $1 / 20$ に減少した。 そもそも 4.2 の実験におい て印加した擬似ノイズは $1 \mathrm{MHz}$ を $600 \mathrm{~Hz}$ で変調したバ 一スト波であり，この波形を検出しているとすれば，スペ クトルとしては $1 \mathrm{MHz} \pm 600 \mathrm{~Hz}$ の場所にしかピーク は現れず，低周波領域で動作する FLL-L では観測できな いはずである。これは，SQUID の $\Phi-V$ 特性の非線形性に

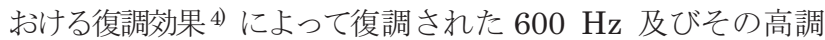
波のピークが出現したと考えられる．このように，SQUID 磁束計を利用する際にはその周波数帯域よりも高い周波数 の磁気ノイズの干渉を受けることがあるが，本手法によっ て，このようなノイズの干渉も緩和できることが分かった．

また， $60 \mathrm{~Hz}$ とその高調波にもピークが観測されているが，こ れは商用電源による影響と考えられる.ここで, FLL-H が ON の 時には $60 \mathrm{~Hz}$ の 2 倍波である $120 \mathrm{~Hz}$ のピークが大きく減少して いる. 通常，商用電源ラインからは $50 \mathrm{~Hz}$ または $60 \mathrm{~Hz}$ の基本波 と，主に奇数次の高調波が磁気ノイズとして観測される.これに 対し, スイッチング電源やディスプレイなどの SQUID 磁束計に 比ベて強電力な高周波デバイスが SQUID センサの近くにあるよ うな特殊な場合において，これらの影響が偶数次の高調波ノイズ として観測されることがある. Fig.5 では，FLL-H が OFF の場 合には変調された高周波ノイズが $120 \mathrm{~Hz}$ にピークとして観測さ れ，FLL-H が ON の場合には高周波ノイズの影響が FLL-H によ って緩和されたものと考えられる.

Fig.5 において FLL-L のホワイトノイズレベルは, FLL-H の ON と OFF でほとんど変わらず, FLL-H が FLL-L に干渉してい ないことが分かる. FLL-H のプレアンプに使用した高速アンプは $1 / f$ コーナ一周波数が約 $10 \mathrm{kHz}$ であった. 仮にこのアンプを用い て従来型の FLL 回路を構成した場合，高帯域は得られるが，100 $\mathrm{Hz}$ 程度までの信号を対象とする生体磁気計測には利用できない. 低周波と高周波を分離することによって，低周波域で低いノイズ レベルを保ったまま，高周波ノイズの影響を緩和できる手法で女 ると言える。 


\section{6. まとめ}

SQUID 磁束計における高周波ノイズ干渉を軽減するた めの高帯域フィードバック回路に関して検討を行った。本 論文では $1 \mathrm{kHz}$ のSQUID 磁束計に対して, $40 \mathrm{kHz}$ から $4 \mathrm{MHz}$ までの高帯域フィードバック回路を併用する回路 を製作した. SQUID の出力電圧勾配 $(d V / d \Phi)$ における高周 波磁気ノイズの影響や，磁場計測中における高周波磁気， イズの影響などを, 本手法により緩和できることを示した。

謝辞 本研究は文部科学省知的クラスター創成事業・ほく りく健康創造クラスターの支援により行った。

\section{References}

1) Y. Hatsukade, T. Inaba, N. Kasai, Y. Maruno, A. Ishiyama, S. Tanaka: Physica C , 412-414, 1484-1490 (2004).

2) K. Enpuku, A. Ohba, K. Inoue, and T. Q. Yang: Physica $C$, 412-414, 1473-1479 (2004).

3) D. Oyama, K. Kobayashi, M. Yoshizawa, and Y. Uchikawa: IEEE Trans. Magn., 42, 10, 3539-3541 (2006).

4) J. Clarke, A. Braginski: The SQUID Handbook I, Wiley-VCH, (2004).

5) N. Ishikawa, K.Nagata, H. Sato, N.Kasai, and S. Kiryu: IEEE Trans. Appl. Supercond,. 3, 1, 1910 (1993).

6) K. Tashiro, I. Sasada, K. Yoshitomi, K. Kazami: J. Magn. Soc. Jpn., 26, 535-538 (2002).

7) D. Oyama, K. Kobayashi, M. Yoshizawa, Y. Uchikawa, S. Hattersley, and Q. Pankhurst: J. Magn. Soc. Jpn., 32, 92-96 (2008).

8) D. Drung: Supercond. Sci. Technol., 16, 1320-1336 (2003). 